\title{
Bacterial vaginosis, aerobic vaginitis, vaginal inflammation and major Pap smear abnormalities
}

\author{
P. Vieira-Baptista ${ }^{1}$ (D) - J. Lima-Silva ${ }^{1} \cdot$ C. Pinto $^{1} \cdot$ C. Saldanha ${ }^{2} \cdot$ J. Beires $^{1}$ • \\ J. Martinez-de-Oliveira ${ }^{3,4} \cdot$ G. Donders ${ }^{5,6}$
}

Received: 5 October 2015 / Accepted: 13 January 2016 / Published online: 25 January 2016

(C) Springer-Verlag Berlin Heidelberg 2016

\begin{abstract}
The purpose of this investigation was to evaluate the impact of the vaginal milieu on the presence of abnormal Pap smears and a positive human papilloma virus (HPV) test. A cross-sectional study was conducted between June 2014 and May 2015, evaluating the vaginal discharge by fresh wet mount microscopy and comparing these data with Pap smear findings. Wet mount slides were scored for bacterial vaginosis (BV), aerobic vaginitis (AV), presence of Candida and Trichomonas vaginalis. Cytologic evaluation was done on all Pap smears according to the Bethesda criteria. The cobas $\odot$ HPV Test (Roche) was performed for HPV detection. A total of 622 cases were evaluated. The mean age of the patients was $41.6 \pm 10.65$ years (range $21-75$ ). Eighty-three women $(13.3 \%)$ had a cytology result worse than low-grade squamous intraepithelial lesion (LSIL). When comparing this group with the one with normal or minor [atypical squamous cells of undetermined significance (ASC-US) or LSIL] Pap smear abnormalities, there were no differences in the presence of Candida (32.5\% vs. $33.2 \%, p=1.0$ ), absence of
\end{abstract}

P. Vieira-Baptista

pedrovieirabaptista@gmail.com

1 Department of Gynecology and Obstetrics, Centro Hospitalar de São João, Alameda Prof. Hernâni Monteiro, 4200 Porto, Portugal

2 LAP — Laboratório de Anatomia Patológica, Unilabs, Porto, Portugal

3 Faculty of Health Sciences, University of Beira Interior, Covilhã, Portugal

4 Department of Children and Women's Health, Centro Hospitalar da Cova da Beira, Covilhã, Portugal

5 Department of Obstetrics and Gynecology, University Hospital Antwerp, Antwerp, Belgium

6 Femicare Clinical Research for Women, Tienen, Belgium lactobacilli (38.6 \% vs. $32.5 \%, p=0.32)$ or BV (20.5\% vs. $13.2 \%, p=0.09)$. On the other hand, moderate or severe inflammation (msI) $(41.0 \%$ vs. $28.8 \%, p=0,04)$, moderate or severe AV (msAV) $(16.9 \%$ vs. $7.2 \%, p=0.009)$ and $\mathrm{msAV} /$ $\mathrm{BV}(37.3 \%$ vs. $20.0 \%, p=0.001)$ were more common in women with such major cervical abnormalities. No significant association was found between deviations of the vaginal milieu and high-risk HPV infection. The presence of msI or msAV, but not BV, is independently associated with an increased risk of major cervical cytological abnormalities, but not with HPV infection.

\section{Introduction}

Aerobic vaginitis (AV) was first described by Donders et al. in 2002 [1]. It is characterised by the presence of immature epithelial cells, a disturbed population of lactobacilli, the presence of aerobic pathogens and inflammation (evaluated by the number of leucocytes and their toxic appearance). The pathogens involved are enteric bacteria (Escherichia coli, Staphylococcus aureus, group B streptococcus and enterococci), and the lack of oestrogen is also believed to play a role in its origin $[2,3]$. The extreme presentation of $\mathrm{AV}$ is comparative to what is known as 'desquamative inflammatory vaginitis' (DIV) [2, 4]. It is postulated that AV is the aerobic counterpart of anaerobic bacterial vaginosis (BV). In some cases, mixed presentations (AV and $\mathrm{BV}$ ) can be found, representing either a transient form or prolonged co-infection [3]. Indeed, the vaginal milieu cannot be seen as a static system, but, rather, as a complex dynamic system.

$\mathrm{AV}$ is still not widely known and, so, it is underdiagnosed by many clinicians, and may even have been mistaken as BV in several former studies [5]. Indeed, in major studies discussing the role of a disturbed vaginal flora in preterm 
labour, AV has hardly ever been acknowledged as a potential risk factor [6, 7], despite its clear pathogenic role [3, 8-12]. Hence, the lack of recognition of AV may explain some of the conflicting results found among studies involving BV.

$\mathrm{AV}$, being present in $2-12 \%$ of women [13-16], has been implied as a possible cause of serious adverse gynaecological and obstetric outcomes, such as an increased risk to acquire sexually transmitted diseases (including human immunodeficiency virus) [17], premature rupture of membranes, preterm labour and ascending chorioamnionitis [18].

Jahic et al. [19], in 2013, added to this list an increased risk of having a low-grade squamous intraepithelial lesion (LSIL) Pap smear result. These authors concluded that the association was independent of being high-risk human papilloma virus (HR-HPV) positive, and that treating $\mathrm{AV}$ would decrease the number of abnormal Pap test results.

The role of persistent infection by one of the high-risk HPVs in the development of cervical cancer is well established [20]. Although the infection is common, few patients develop high-grade lesions or invasive cancer. As the progression risk is still poorly understood, several factors need to be investigated, including smoking, contraception, presence of sexually transmitted diseases, as well as factors from the vaginal milieu [21].

Clarke et al. have shown that a high $\mathrm{pH}$, indicative of an abnormal vaginal flora, is a risk factor for HPV infection and abnormal Pap tests (LSIL) [22]. This relation was more marked in women under 35 and over 65 years old, and was assumed to be associated with BV.

However, an elevated $\mathrm{pH}$ is not always indicative of BV. The relation between increased vaginal $\mathrm{pH}$ and vaginal abnormalities, the lactobacillary flora profiles and $\mathrm{AV}$ is better accomplished by using wet mount, rather than Gram stain [23].

The aim of this paper is to investigate the correlation between the vaginal flora in wet mounts and major Pap test abnormalities.

\section{Materials and methods}

Between June 2014 and May 2015, we performed microscopic examination of vaginal discharge collected from 622 consecutive patients, who attended the clinic with an indication for cervical Pap test (cross-sectional study). After the insertion of an unmoistened speculum, discharge from the lateral upper third of the vaginal wall was collected with a spatula and spread onto a glass slide. The slides were then allowed to dry and later rehydrated with a drop of saline [24]. All samples were evaluated blindly by one of the authors (PV-B), according to Femicare's criteria $[8,25]$. It included: lactobacillary grade evaluation (grade 0: no lactobacilli or other bacteria; grade I: lactobacillary flora, no other bacteria; grade IIa: lactobacilli dominating flora, but with other bacteria; grade
IIb: lactobacilli present, but other bacteria dominating; grade III: absent lactobacilli, other bacteria present); presence of 'clue cells'; leucocytes ( $\leq 10$ /high-power field, $>10$ /highpower field and $\leq 10$ /epithelial cell, $>10 /$ epithelial cell); proportion of toxic leucocytes (none or sporadic, $\leq 50 \%$ of leucocytes, $>50 \%$ of leucocytes); background flora (unremarkable or cytolysis, small coliform bacilli, cocci or chains, anaerobic); proportion of parabasal epitheliocytes (none or $<1 \%, \leq 10 \%,>10 \%$ ); presence of Candida spp. (spores/ blastospores, hyphae/pseudohyphae); presence of structures compatible with Trichomonas vaginalis.

Moderate or severe inflammation (msI) was defined as more than 10 leucocytes per high-power field and more than 10 leucocytes per epithelial cell, respectively. Moderate or severe aerobic vaginitis (msAV) was defined as an $\mathrm{AV}$ score of more than 4 , according to the original definition of Donders [8]. The parameters evaluated to determine the AV score were: lactobacillary grade, number of leucocytes, proportion of toxic leucocytes, background flora and proportion of parabasal cells. Atrophic vaginitis was defined by the presence of parabasal cells, as the predominant cell type, and leucocytes or, in some cases, a paucity of cells, usually with lack of lactobacilli.

All Pap tests (liquid-based cytology, ThinPrep medium, Hologic, Bedford, MA, USA) were read at the institution's laboratory according to the Bethesda criteria [26]. The cobas $(\subset$ HPV Test (Roche Molecular Systems Inc., Pleasanton, CA, USA) was performed for all patients, according to the institution's protocol.

Most women (85.5\%) were recruited from the Cervical Pathology Unit and the remainder from the Family Planning Services.

After explanation of the study and obtaining informed consent, a clinical history, including contraceptive methods, hormonal treatments, hormonal status, vulvovaginal symptoms, smoking habits, comorbidities, history of cervical disease and conization were recorded. In patients with symptoms (e.g. pruritus, burning or discharge), vulvar dermatoses were excluded by thorough clinical examination, performed by clinicians with expertise in this area, before attributing these symptoms to 'vaginitis.'

Exclusion criteria were age less than 21 years old, pregnancy, total hysterectomy, vaginal bleeding and vaginal medication within the last $48 \mathrm{~h}$ or refusal to participate in the study.

Whenever an immediate diagnosis was necessary (symptomatic vaginitis), two slides were taken: one for immediate diagnosis and an additional one to be read blindly together with the other slides. All diagnosed vaginitis were treated according to the lege artis.

According to the Bethesda classification, 'major Pap smear abnormality' (MPSA) was defined as any cellular abnormality more severe than LSIL: LSIL cannot exclude high-grade intraepithelial neoplasia (LSIL-H) [26], atypical glandular 
cells (AGC), atypical squamous cells cannot exclude highgrade intraepithelial lesion (ASC-H), high-grade intraepithelial lesion (HSIL), adenocarcinoma in situ (AIS), carcinoma. At the time of the study, the now no longer recommended subtype 'LSIL-H' [26] was still being used at our institution and was included in the major abnormalities group. The cases with cytology showing negative for intraepithelial lesion or malignancy (NILM), ASC-US or LSIL composed the control group.

According to the study protocol, colposcopy-driven biopsies were taken at the physician's discretion. The available biopsy results (punch biopsies and excisional procedures) were also evaluated. These results were available for 190 $(30.5 \%)$ women and were classified as normal, cervical intraepithelial neoplasia (CIN) 1, CIN2, CIN3, carcinoma, adenocarcinoma in situ or adenocarcinoma.

The study was approved by the Ethics Committee of the Centro Hospitalar de São João (number 266-2014).

Statistical analysis was performed using Microsoft ${ }^{\circledR}$

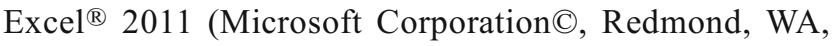
USA) and IBM ${ }^{\circledR}$ SPSS $^{\circledR} 20.0$ (IBM Corporation ${ }^{\circledR}$, Armonk, NY, USA). The Student's $t$-test was used for continuous variables and the Fisher's exact test was used for categorical variables. A $p$-value $<0.05$ was considered statistically significant.

\section{Results}

The mean age was $41.6 \pm 10.65$ years (range $21-75)(n=622)$. There were 83 (13.3\%) women with MPSA (case group) (Table 1), most of whom [95.2\% (79/83)] were enrolled at the Cervical Pathology Unit.

The characteristics of the two groups are summarised in Table 2. There were no differences between the control and study groups in terms of age, contraceptive use, menopause status, use of hormonal replacement therapy or the presence of symptoms suggestive of vaginitis.

Table 1 Distribution of the Pap test results

\begin{tabular}{ll}
\hline & $n(\%)$ \\
\hline NILM & $367(59.0 \%)$ \\
ASC-US & $81(13.0 \%)$ \\
LSIL & $91(14.6 \%)$ \\
LSIL-H & $12(1.9 \%)$ \\
ASC-H & $3(0.5 \%)$ \\
HSIL & $65(10.5 \%)$ \\
AGC & $1(0.2 \%)$ \\
AIS & $1(0.2 \%)$ \\
Carcinoma & $1(0.2 \%)$ \\
Total & $622(100 \%)$ \\
\hline
\end{tabular}

Patients in the study group were significantly more likely to be smokers, but less likely to have had a previous cervical excisional procedure. In the control group, a significant number of patients $[24.5 \%(132 / 539)]$ had already been treated with previous conization, and were in the follow-up phase now.

There was no association between AV and smoking [ $6.0 \%$ $(5 / 83) \mathrm{AV}$ in smokers vs. $7.4 \%(24 / 326)$ in non-smokers, $p=0.813]$. On the other hand, the percentage of $\mathrm{BV}$ among smokers was somewhat higher, but without reaching statistical significance $[21.7 \%(18 / 83)$ vs. $13.8 \%(45 / 326), p=0.088]$.

The presence of msAV was significantly more common in the MPSA group than in the control group $(16.9 \%$ vs. $7.2 \%$, $p=0.009)$ and the same was true for msI (41.0\% vs. $28.8 \%$, $p=0.029$ ). Also, if women with moderate or severe $\mathrm{AV}$ and/or $\mathrm{BV}$ were considered jointly ( $\mathrm{ms} \mathrm{AV} / \mathrm{BV}$ ), these abnormal flora conditions were more frequent in women with MPSA than in women with LSIL, ASC-US or NILM (37.3\% vs. $20.0 \%$, $p=0.001)$. The prevalence of single $\mathrm{BV}$, however, was somewhat higher in the study group, but without reaching statistical significance (20.5\% vs. $13.2 \%, p=0.090$, Table 3$)$.

Lactobacilli were absent (lactobacillary grades 0 and III) in $12.3 \%(51 / 415)$ of women with MPSA and in $15.5 \%(32 /$ 207) of control women $(p=0.3)$.

Eighty-nine (47.1\%) of the 189 women with msI had Candida, 48 (25.4\%) had msAV, 22 (11.6\%) showed T. vaginalis and $16(8.5 \%)$ had atrophic vaginitis.

Considering the cases of Candida and stratifying it according to the presence of inflammation, there was still no difference in the risk of MPSA [13.5\% (12/89) vs. $12.8 \%(15 / 117)$, $p=1.0]$.

In women with inflammation, if more than $50 \%$ of the leucocytes were toxic, the rate of MPSA was $23.3 \%$ (17/ $73)$, compared to $12.0 \%(66 / 549)$ in women with lower numbers of toxic leucocytes $(p=0.016)$.

The rate of AV was $7.9 \%(29 / 367)$ in LSIL and $8.8 \%$ $(8 / 91)$ in NILM $(p=0.8)$.

The HPV test results were available in 609 (97.9\%) women. There was no relation between the presence of HR-HPV and msAV, inflammation or BV (Table 4).

Amongst women with HR-HPV, msAV was significantly more common if they also had MPSA, as compared to HRHPV positive women with a Pap smear LSIL or less $[17.3 \%$ $(13 / 75)$ vs. $7.7 \%(15 / 194), p=0.025]$. Women with HR-HPV had a non-significantly higher chance to have BV than HRHPV women with low-grade or normal cytology [21.6 \% (16/ $74)$ vs. $12.4 \%(24 / 194), p=0.083]$.

Of women who had additional information about pathology results of cervical biopsies, CIN2+ was present in $77.8 \%$ (7/9) of those with msAV and in $74.5 \%(35 / 47)$ of those without msAV $(p=0.2)$. Of all women, CIN2+ was present in $40 \%(10 / 25)$ of those with msAV and in $30.1 \%(50 / 166)$ of those without msAV $(p=0.4)$. 
Table 2 Characteristics of the two groups (Pap test LSIL or less vs. Pap test worse than LSIL)

\begin{tabular}{llll}
\hline & Pap test $\leq$ LSIL & Pap test $>$ LSIL & $p$-Value \\
\hline Mean age (years) & $41.6 \pm 10.78$ & $41.4 \pm 9.82$ & 0.875 \\
Enrolled at the Cervical Pathology Unit & $84.0 \%(453 / 539)$ & $95.2 \%(79 / 83)$ & $\mathbf{0 . 0 0 7}$ \\
Contraceptive use & & & \\
$\quad$ - None & $25.8 \%(108 / 419)$ & $29.6 \%(21 / 71)$ & 0.501 \\
- Oral contraceptives & $39.1 \%(164 / 419)$ & $35.2 \%(25 / 71)$ & 0.529 \\
- Progestin-only pill & $6.2 \%(26 / 419)$ & $2.8 \%(2 / 71)$ & 0.255 \\
- Intrauterine device & $11.9 \%(50 / 419)$ & $11.3 \%(8 / 71)$ & 0.872 \\
- Subdermal implant & $4.1 \%(17 / 419)$ & $5.6 \%(4 / 71)$ & 0.544 \\
- Vaginal ring & $0.7 \%(3 / 419)$ & $0 \%(0 / 71)$ & 0.474 \\
- Male condom & $4.3 \%(18 / 419)$ & $4.2 \%(3 / 71)$ & 0.978 \\
$\quad$ - Tubal ligation & $7.9 \%(33 / 419)$ & $11.3 \%(8 / 71)$ & 0.340 \\
Menopause & $22.4 \%(121 / 539)$ & $14.4 \%(12 / 83)$ & 0.114 \\
$\quad$ - With hormonal replacement therapy & $8.5 \%(10 / 117)$ & $9.1 \%(1 / 11)$ & 0.951 \\
Smoking & $18.6 \%(67 / 360)$ & $32.6 \%(16 / 49)$ & $\mathbf{0 . 0 2 1}$ \\
'Vaginitis' symptoms & $4.8 \%(26 / 539)$ & $4.8 \%(4 / 83)$ & 1.000 \\
Cervical excisional procedure & $24.5 \%(132 / 539)$ & $10.8 \%(9 / 83)$ & $\mathbf{0 . 0 0 5}$ \\
\hline
\end{tabular}

\section{Discussion}

$\mathrm{AV}$ is a highly prevalent condition, with specific criteria that can be easily recognised through wet mount microscopy [24].

$\mathrm{BV}$ has been extensively debated in the literature as a risk factor for cervical dysplasia [27] and cancer [28]. On the contrary, little is known about the role of AV. When interpreting the data relative to $\mathrm{BV}$, it must be kept in mind that $\mathrm{AV}$ was not recognised or was ignored in most of these older studies, while in others it might even have been mistaken as BV [29].

The role of (chronic) inflammation in the development of pre-cancerous lesions has been gaining increasing attention in the recent years [30-32]. According to the literature, the interleukin (IL) profile of AV (increased IL-1b, IL-6 and IL-8) is similar to what is found in women with cervical intraepithelial neoplasia [33-36]. In contrast, in BV, IL-6 and IL-8 are not expressed [37].
Our data has shown a relation between $\mathrm{AV}, \mathrm{AV}$ and/or BV, but not isolated BV, and a Pap test with major abnormalities. There was also an association between msI and a Pap test with major abnormalities. The majority of the cases with msI were not in the context of $\mathrm{AV}$, pointing to the role of the inflammatory response as such, and its own relevance, rather than the presence of infectious agents, which, in some cases, can be commensals of the vagina. Already in 2001, Castle et al. [36] found a non-significant relation between the presence of inflammation and high-grade CIN [odds ratio (OR), 1.9; $95 \%$ confidence interval (CI), 0.91-4.1) on Pap smears.

The annotation 'inflammation' can have different meanings: it can be more or less exuberant and there can be significant differences in terms of the presence of toxic leucocytes. Indeed, we found that not only is inflammation linked to major abnormal Pap smear results, but also that the presence of

Table 3 Prevalence of the presence of Candida spp., bacterial vaginosis, Trichomonas vaginalis, aerobic vaginitis, absent lactobacilli, inflammation or aerobic vaginitis/bacterial vaginosis according to the Pap test results

\begin{tabular}{|c|c|c|c|c|c|c|}
\hline & \multicolumn{3}{|l|}{ Pap test result } & \multicolumn{3}{|l|}{ Pap test result } \\
\hline & NILM & $>$ NILM & $p$-value & $\leq \mathrm{LSIL}$ & $>$ LSIL & $p$-value \\
\hline Candida spp. & $35.7 \%(131 / 367)$ & $29.4 \%(75 / 255)$ & 0.119 & $33.2 \%(179 / 539)$ & $32.5 \%(27 / 83)$ & 1.000 \\
\hline Bacterial vaginosis $(\mathrm{BV})$ & $12.5 \%(46 / 367)$ & $16.5 \%(42 / 255)$ & 0.198 & $13.2 \%(71 / 539)$ & $20.5 \%(17 / 83)$ & 0.090 \\
\hline Trichomonas vaginalis & $3.8 \%(14 / 366)$ & $2.7 \%(7 / 256)$ & 0.507 & $3.2 \%(17 / 539)$ & $4.8 \%(4 / 83)$ & 0.508 \\
\hline msAV & $7.9 \%(29 / 367)$ & $9.4 \%(24 / 255)$ & 0.560 & $7.2 \%(39 / 539)$ & $16.9 \%(14 / 83)$ & 0.009 \\
\hline Absent lactobacilli & $34.1 \%(125 / 367)$ & $32.2 \%(82 / 255)$ & 0.666 & $32.5 \%(175 / 539)$ & $38.6 \%(32 / 83)$ & 0.317 \\
\hline Inflammation (msI) & $31.6 \%(116 / 367)$ & $28.6 \%(73 / 255)$ & 0.478 & $28.8 \%(155 / 539)$ & $41.0 \%(34 / 83)$ & 0.029 \\
\hline msAV and/or BV & $20.2 \%(74 / 367)$ & $25.5 \%(65 / 255)$ & 0.119 & $20.0 \%(108 / 539)$ & $37.3 \%(31 / 83)$ & 0.001 \\
\hline
\end{tabular}


Table 4 HPV relation with the presence or absence of msAV; $H R$ high risk

\begin{tabular}{llllll}
\hline & & msAV & $p$-Value & BV & $p$-Value \\
\hline HR-HPV (any) & Positive & $10.4 \%(28 / 268)$ & 0.194 & $14.9 \%(40 / 268)$ & 0.640 \\
& Negative & $7.3 \%(25 / 341)$ & & $13.5 \%(46 / 341)$ & \\
HPV16 & Positive & $12.3 \%(9 / 73)$ & 0.266 & $13.7 \%(10 / 73)$ & 1.000 \\
& Negative & $8.2 \%(44 / 536)$ & & $14.2 \%(76 / 536)$ & \\
HPV18 & Positive & $10.5 \%(2 / 19)$ & 0.677 & $5.3 \%(1 / 19)$ & 0.498 \\
& Negative & $8.6 \%(51 / 590)$ & & $14.4 \%(85 / 590)$ & \\
HR-HPV (other) & Positive & $10.2 \%(21 / 206)$ & 0.364 & $16.5 \%(34 / 206)$ & 0.268 \\
& Negative & $7.9 \%(32 / 403)$ & & $12.9 \%(52 / 403)$ & \\
HR-HPV positive & Pap $\leq$ LSIL & $7.7 \%(15 / 194)$ & $\mathbf{0 . 0 2 5}$ & $12.4 \%(24 / 194)$ & 0.083 \\
& Pap > LSIL & $17.6 \%(13 / 74)$ & & $21.6 \%(16 / 74)$ & \\
HR-HPV negative & Pap $\leq$ LSIL & $7.2 \%(24 / 333)$ & 0.460 & $13.5 \%(45 / 333)$ & 1.000 \\
& Pap>LSIL & $12.5 \%(1 / 8)$ & & $12.5 \%(1 / 8)$ & \\
\hline
\end{tabular}

toxic leucocytes had a stronger association with more severe cervical cytologic abnormalities.

The thesis that a chronic inflammation in the vagina decreases the innate immune response in the cervix, allowing for persistence of HPV infection and increasing the progression to high-grade lesions, deserves further study. This theory would fit with the observation that, in some series, anti-inflammatory drugs were associated with a decreased risk of cervical cancer $[38,39]$.

Despite the fact that a low $\mathrm{pH}$ and the presence of lactobacilli are considered an important part of the defence system of the vagina [40] and that it might also be true for the cervix [41], we could not establish an association between lactobacilli absence and an abnormal Pap test result. This may be explained by the fact that the absence of lactobacilli can be due to a variety of reasons, including AV, BV, Trichomonas infection, severely inflamed candidosis etc., but also due to hormonal influences like after menopause or during the postpartum period [42-44]. Hence, the absence of lactobacilli in the vagina cannot always be considered pathological [45].

We could not confirm the results of Jahic et al. [19], who found AV to be more common in women with LSIL when compared to women with NILM. In our study, the rate of AV was similar in women with LSIL and NILM. A possible explanation for these different findings may be that Pap tests in that study could be collected for a period of up to 6 months before the wet mount smear was taken. Since both cervical dysplasia and vaginal flora are dynamic, it may indicate that, in women with minor Pap smear abnormalities, like LSIL, regression of AV may be more likely than in women with more severe cytological abnormalities, but this is purely hypothetical. Finally, in Jahic et al.'s study, no information was given about the AV prevalence in women with major cytological abnormalities.

Although it is tempting to explain our findings by immune system interactions, it is also possible that the presence of $\mathrm{AV}$ leads to a misreading of the Pap smear and an overdiagnosis of
MPSA. Indeed, the presence of inflammation, atrophy or reparative phenomena - all of which can be found in AV - can, perhaps, influence the Pap test interpretation, rendering it merely a confounder instead of being a risk factor.

$\mathrm{AV}, \mathrm{BV}$, elevated vaginal $\mathrm{pH}$ and the presence of inflammation can also be markers of sexual activity or of specific habits, like smoking, that are known to increase the risk of having an abnormal Pap test. Women participating in this study were not interrogated about their sexual habits.

Smoking, as expected, was associated with having a Pap test with a major abnormality. Smoking is known to be associated with cervical dysplasia, cancer and also with BV, making it difficult to interpret the independent role of each of the factors, as BV can be a marker of smoking. However, for AV, we could not find such a relation with smoking.

Despite the small numbers of biopsies, the rate of CIN2+ in patients with a Pap test worse than LSIL was similar in both women with and without $\mathrm{AV}$, thus ruling out the hypothesis that increased prevalence of $\mathrm{AV}$ in women with abnormal cytology could be due to 'false-positives.' This can be a phenomenon similar to the increased risk of false-positive ASCUS Pap smear in women with $T$. vaginalis infection [46].

However, we did not find an association between the presence of $T$. vaginalis and an abnormal Pap test.

Also we found no relation between the presence of microscopic candidosis and high-grade lesions of the cervix, not even after correcting for the presence of concurrent inflammation.

Although reporting the presence of inflammation and microorganisms in the Pap test may lead to unnecessary treatment and interventions [47], our data seem to indicate that reporting vaginal infectious conditions and inflammation on Pap smear analyses should be done systematically. For AV, however, Pap readings are not properly validated to provide a full diagnosis, but inflammatory cells can be easily recognised and graded [48, 49], at least on conventional Pap smears. Hence, specific Pap test criteria for the diagnosis of 
$\mathrm{AV}$, inflammation and BV should be developed and advocated, also for the new, liquid-based cytology testing.

The weak points of this study may include the fact most women were enrolled at a Cervical Pathology Unit, which enabled to have an enriched sample of abnormal Pap tests. A significant proportion of these women had a history of cervical disease and a high percentage of previous excisional procedures of the cervix, which may have distorted the 'natural' prevalence of lesions and HR-HPV in the studied women. Indeed, in many women with original high-grade lesions, not only the lesion but also the HR-HPV disappeared at later follow-up.

Despite comparing the results of a cervical and a vaginal collection (Pap test and wet mount, respectively), the effects of the vaginal milieu are, without any doubt, also exerted on the cervix. Furthermore, there is a strong concordance between the microbiome found in the cervix and the vagina [50].

Another disadvantage may be that we most likely underreported the presence of trichomoniasis, due to delayed reading of the wet mounts and on candidosis, as, according to some authors, sensitivity on wet mounts may be less than that with cultures [51, 52].

Finally, the analysis based on histological biopsy results can be biased, as no systematic biopsies were performed.

\section{Conclusion}

Aerobic vaginitis (AV) is a significant cause of vaginitis-like symptoms, which no longer can be ignored or neglected. Among other important adverse gynaecological and obstetrical outcomes, it may also be involved in the progression to cervical intraepithelial neoplasia and cancer in high-risk human papilloma virus (HR-HPV) positive women. This can be due to its chronic inflammatory features, leading to depression of the innate immune response mechanisms. The interleukin (IL) profile that has been associated with $\mathrm{AV}$ is coherent with that found in HR-HPV infected patients progressing to cervical dysplasia and cancer.

There was no association between the presence of $A V$ and that of HR-HPV infection, so AV is probably not related to an increased acquisition risk of the latter. Hence, more likely, AV and inflammation can have a permissive role in the persistence of HR-HPV and in progression to high-grade lesions once established.

Currently, it is not clear whether $\mathrm{AV}$ is a marker or a risk factor, but our data suggest that inflammation plays a key role. Remarkably, not all types of 'inflammation' are equally dangerous, as, opposed to $\mathrm{AV}$, inflammation associated with Candida was not associated with an increased risk.

Bacterial vaginosis (BV), which is not associated with inflammation, was, in our study, also not significantly associated with abnormal Pap test results.
Compliance with ethical standards No funding or sponsorship was received by the authors for this research.

Conflict of interest The authors declare that they have no conflict of interest.

\section{References}

1. Donders GGG, Vereecken A, Bosmans E, Dekeersmaecker A, Salembier G, Spitz B (2002) Definition of a type of abnormal vaginal flora that is distinct from bacterial vaginosis: aerobic vaginitis. BJOG 109(1):34-43. http://www.ncbi.nlm.nih.gov/pubmed/ 11845812. Accessed May 15, 2015

2. Sobel JD (1994) Desquamative inflammatory vaginitis: a new subgroup of purulent vaginitis responsive to topical $2 \%$ clindamycin therapy. Am J Obstet Gynecol 171(5):1215-1220. http://www.ncbi. nlm.nih.gov/pubmed/7977522. Accessed June 29, 2015

3. Donders G, Bellen G, Rezeberga D (2011) Aerobic vaginitis in pregnancy. BJOG 118(10):1163-1170. doi:10.1111/j.1471-0528. 2011.03020.x

4. Newbern EC, Foxman B, Leaman D, Sobel JD (2002) Desquamative inflammatory vaginitis: an exploratory case-control study. Ann Epidemiol 12(5):346-352. http://www.ncbi.nlm.nih. gov/pubmed/12062923. Accessed June 29, 2015

5. Han C, Wu W, Fan A et al (2015) Diagnostic and therapeutic advancements for aerobic vaginitis. Arch Gynecol Obstet 291(2): 251-257. doi:10.1007/s00404-014-3525-9

6. Sangkomkamhang US, Lumbiganon P, Prasertcharoensuk W, Laopaiboon M (2015) Antenatal lower genital tract infection screening and treatment programs for preventing preterm delivery. Cochrane Database Syst Rev 2, CD006178. http://www.ncbi.nlm. nih.gov/pubmed/25922860. Accessed April 30, 2015

7. Hauth JC, Macpherson C, Carey JC et al (2003) Early pregnancy threshold vaginal $\mathrm{pH}$ and Gram stain scores predictive of subsequent preterm birth in asymptomatic women. Am J Obstet Gynecol 188(3):831-835. http://www.ncbi.nlm.nih.gov/pubmed/12634666. Accessed June 29, 2015

8. Donders GGG (2007) Definition and classification of abnormal vaginal flora. Best Pract Res Clin Obstet Gynaecol 21(3):355373. doi:10.1016/j.bpobgyn.2007.01.002

9. Donders GGG, Vereecken A, Bosmans E, Spitz B (2003) Vaginal cytokines in normal pregnancy. Am J Obstet Gynecol 189(5):14331438. http://www.ncbi.nlm.nih.gov/pubmed/14634582. Accessed June 29, 2015

10. Nenadić DB, Pavlović MD (2008) Cervical fluid cytokines in pregnant women: relation to vaginal wet mount findings and polymorphonuclear leukocyte counts. Eur J Obstet Gynecol Reprod Biol 140(2):165-170. doi:10.1016/j.ejogrb.2008.02.020

11. Donders GG, Van Calsteren K, Bellen G et al (2009) Predictive value for preterm birth of abnormal vaginal flora, bacterial vaginosis and aerobic vaginitis during the first trimester of pregnancy. BJOG 116(10):1315-1324. doi:10.1111/j.1471-0528.2009.02237.x

12. McDonald HM, O'Loughlin JA, Jolley P, Vigneswaran R, McDonald PJ (1991) Vaginal infection and preterm labour. Br J Obstet Gynaecol 98(5):427-435. http://www.ncbi.nlm.nih.gov/ pubmed/2059587. Accessed June 30, 2015

13. Villaseca R, Ovalle A, Amaya F et al (2015) Vaginal infections in a family health clinic in the metropolitan region, Chile. Rev Chilena Infectol 32(1):30-36. doi:10.4067/S0716-10182015000200007

14. Tomusiak A, Heczko PB, Janeczko J, Adamski P, Pilarczyk-Zurek M, Strus M (2013) Bacterial infections of the lower genital tract in fertile and infertile women from the southeastern Poland. Ginekol Pol 84(5):352-358. http://www.ncbi.nlm.nih.gov/pubmed/ 23819400. Accessed June 29, 2015 
15. Bologno R, Díaz YM, Giraudo MC et al (2011) Importance of studying the balance of vaginal content (BAVACO) in the preventive control of sex workers. Rev Argent Microbiol 43(4):246-250. doi:10.1590/S0325-75412011000400002

16. Tansarli GS, Kostaras EK, Athanasiou S, Falagas ME (2013) Prevalence and treatment of aerobic vaginitis among nonpregnant women: evaluation of the evidence for an underestimated clinical entity. Eur J Clin Microbiol Infect Dis 32(8):977-984. doi: 10.1007/s10096-013-1846-4

17. Donders G, De Wet HG, Hooft P, Desmyter J (1993) Lactobacilli in Papanicolaou smears, genital infections, and pregnancy. Am J Perinatol 10(5):358-361. doi:10.1055/s-2007-994761

18. Donders GG, Moerman P, De Wet GH, Hooft P, Goubau P (1991) The association between Chlamydia cervicitis, chorioamnionitis and neonatal complications. Arch Gynecol Obstet 249(2):79-85. http://www.ncbi.nlm.nih.gov/pubmed/1953055. Accessed June 30,2015

19. Jahic M, Mulavdic M, Hadzimehmedovic A, Jahic E (2013) Association between aerobic vaginitis, bacterial vaginosis and squamous intraepithelial lesion of low grade. Med Arch 67(2): 94-96. http://www.ncbi.nlm.nih.gov/pubmed/24341052. Accessed June 21, 2015

20. Cogliano V, Baan R, Straif K, Grosse Y, Secretan B, El Ghissassi F; WHO International Agency for Research on Cancer (2005) Carcinogenicity of human papillomaviruses. Lancet Oncol 6(4): 204. http://www.ncbi.nlm.nih.gov/pubmed/15830458. Accessed July 1,2015

21. Gillet E, Meys JF, Verstraelen $H$ et al (2011) Bacterial vaginosis is associated with uterine cervical human papillomavirus infection: a meta-analysis. BMC Infect Dis 11(1):10. doi:10.1186/1471-2334-11-10

22. Clarke MA, Rodriguez AC, Gage JC et al (2012) A large, population-based study of age-related associations between vaginal $\mathrm{pH}$ and human papillomavirus infection. BMC Infect Dis 12:33. doi:10.1186/1471-2334-12-33

23. Donders GG, Vereecken A, Dekeersmaecker A, Van Bulck B, Spitz B (2000) Wet mount microscopy reflects functional vaginal lactobacillary flora better than Gram stain. J Clin Pathol 53(4): 308-313. http://www.ncbi.nlm.nih.gov/pubmed/10823128. Accessed July 3, 2015

24. Donders GGG, Larsson PG, Platz-Christensen JJ, Hallén A, van der Meijden W, Wölner-Hanssen P (2009) Variability in diagnosis of clue cells, lactobacillary grading and white blood cells in vaginal wet smears with conventional bright light and phase contrast microscopy. Eur J Obstet Gynecol Reprod Biol 145(1):109-112. doi: 10.1016/j.ejogrb.2009.04.012

25. Donders GGG, Marconi C, Bellen G, Donders F, Michiels T (2015) Effect of short training on vaginal fluid microscopy (wet mount) learning. J Low Genit Tract Dis 19(2):165-169. doi:10.1097/LGT. 0000000000000052

26. Nayar R, Wilbur DC (2015) The Pap test and Bethesda 2014. "The reports of my demise have been greatly exaggerated." (after a quotation from Mark Twain). Acta Cytol 59(2):121-132. doi:10.1159/ 000381842

27. Gillet E, Meys JFA, Verstraelen H et al (2012) Association between bacterial vaginosis and cervical intraepithelial neoplasia: systematic review and meta-analysis. PLoS One 7(10), e45201. doi:10.1371/ journal.pone. 0045201

28. Mikamo H, Sato Y, Hayasaki Y et al (1999) Intravaginal bacterial flora in patients with uterine cervical cancer. High incidence of detection of Gardnerella vaginalis. J Infect Chemother 5(2):8285. doi:10.1007/s101569900002

29. Donders GG (1999) Bacterial vaginosis during pregnancy: screen and treat? Eur J Obstet Gynecol Reprod Biol 83(1):1-4. http://www.ncbi. nlm.nih.gov/pubmed/10221601. Accessed August 7, 2015

30. Fernandes JV, DE Medeiros Fernandes TAA, DE Azevedo JCV et al (2015) Link between chronic inflammation and human papillomavirus-induced carcinogenesis (Review). Oncol Lett 9(3): 1015-1026. doi:10.3892/ol.2015.2884

31. Adefuye A, Sales K (2012) Regulation of inflammatory pathways in cancer and infectious disease of the cervix. Scientifica (Cairo) 2012, 548150. doi:10.6064/2012/548150

32. Boccardo E, Lepique AP, Villa LL (2010) The role of inflammation in HPV carcinogenesis. Carcinogenesis 31(11):1905-1912. doi:10. 1093/carcin/bgq176

33. Behbakht K, Friedman J, Heimler I, Aroutcheva A, Simoes J, Faro S (2002) Role of the vaginal microbiological ecosystem and cytokine profile in the promotion of cervical dysplasia: a case-control study. Infect Dis Obstet Gynecol 10(4):181-186. doi:10.1155/ S1064744902000200

34. Kemp TJ, Hildesheim A, García-Piñeres A et al (2010) Elevated systemic levels of inflammatory cytokines in older women with persistent cervical human papillomavirus infection. Cancer Epidemiol Biomarkers Prev 19(8):1954-1959. doi:10.1158/10559965.EPI-10-0184

35. Iwata T, Fujii T, Morii $\mathrm{K}$ et al (2015) Cytokine profile in cervical mucosa of Japanese patients with cervical intraepithelial neoplasia. Int J Clin Oncol 20(1):126-133. doi:10.1007/s10147-014-0680-8

36. Castle PE, Hillier SL, Rabe LK et al (2001) An association of cervical inflammation with high-grade cervical neoplasia in women infected with oncogenic human papillomavirus (HPV). Cancer Epidemiol Biomarkers Prev 10(10):1021-1027. http://www.ncbi. nlm.nih.gov/pubmed/11588127. Accessed July 5, 2015

37. Marconi C, Donders GGG, Bellen G, Brown DR, Parada CMGL, Silva MG (2013) Sialidase activity in aerobic vaginitis is equal to levels during bacterial vaginosis. Eur J Obstet Gynecol Reprod Biol 167(2):205-209. doi:10.1016/j.ejogrb.2012.12.003

38. Friel G, Liu CS, Kolomeyevskaya NV et al (2015) Aspirin and acetaminophen use and the risk of cervical cancer. J Low Genit Tract Dis 19(3):189-193. doi:10.1097/LGT.0000000000000104

39. Mitchell A, Newton JM, Brite K et al (2007) Cyclooxygenase 2 expression in cervical intraepithelial neoplasia and vulvar cancer. $\mathrm{J}$ Low Genit Tract Dis 11(2):80-85

40. Linhares IM, Summers PR, Larsen B, Giraldo PC, Witkin SS (2011) Contemporary perspectives on vaginal $\mathrm{pH}$ and lactobacilli. Am J Obstet Gynecol 204(2):120.e1-120.e5. doi:10.1016/j.ajog. 2010.07.010

41. Mead PB (1978) Cervical-vaginal flora of women with invasive cervical cancer. Obstet Gynecol 52(5):601-604. http://www.ncbi. nlm.nih.gov/pubmed/364358. Accessed August 7, 2015

42. Pabich WL, Fihn SD, Stamm WE, Scholes D, Boyko EJ, Gupta K (2003) Prevalence and determinants of vaginal flora alterations in postmenopausal women. J Infect Dis 188(7):1054-1058. doi:10. 1086/378203

43. Witkin SS, Linhares IM, Giraldo P (2007) Bacterial flora of the female genital tract: function and immune regulation. Best Pract Res Clin Obstet Gynaecol 21(3):347-354. doi:10.1016/j.bpobgyn. 2006.12.004

44. Yang XL, Yang HX, Duan T et al (2009) Vaginal microflora and relevant factors in puerperium. Zhonghua Fu Chan Ke Za Zhi 44(7):496-499. http://www.ncbi.nlm.nih.gov/pubmed/19957547. Accessed August 7, 2015

45. Petrova MI, Lievens E, Malik S, Imholz N, Lebeer S (2015) Lactobacillus species as biomarkers and agents that can promote various aspects of vaginal health. Front Physiol 6:81. doi:10.3389/ fphys.2015.00081

46. Donders GGG, Depuydt CE, Bogers J-P, Vereecken AJ (2013) Association of Trichomonas vaginalis and cytological abnormalities of the cervix in low risk women. PLoS One 8(12), e86266. doi: 10.1371/journal.pone.0086266

47. Güdücü N, Gönenç $G$, Ișçi $H$, Yiğiter $A B$, Başsüllü N, Dünder I (2012) Clinical importance of detection of bacterial vaginosis, Trichomonas vaginalis, Candida albicans and actinomyces in 
papanicolaou smears. Clin Exp Obstet Gynecol 39(3):333-336. http://www.ncbi.nlm.nih.gov/pubmed/23157037. Accessed August 7, 2015

48. Heller DS, Weiss G, Bittman S, Goldsmith L (2015) Does a diagnosis of atrophic vaginitis on Papanicolaou test signify the presence of inflammation? Menopause 22(8):814-815. doi:10.1097/GME. 0000000000000393

49. Donders GGG, Berger J, Heuninckx H, Bellen G, Cornelis A (2011) Vaginal flora changes on Pap smears after insertion of levonorgestrel-releasing intrauterine device. Contraception 83(4): 352-356. doi:10.1016/j.contraception.2010.08.007

50. Smith WL, Hedges SR, Mordechai E et al (2014) Cervical and vaginal flora specimens are highly concordant with respect to bacterial vaginosis-associated organisms and commensal lactobacillus species in women of reproductive age. J Clin Microbiol 52(8): 3078-3081. doi:10.1128/JCM.00795-14

51. Khatoon R, Jahan N, Ahmad S, Khan HM, Rabbani T (2015) Comparison of four diagnostic techniques for detection of Trichomonas vaginalis infection in females attending tertiary care hospital of North India. Indian J Pathol Microbiol 58(1):36-39. doi: 10.4103/0377-4929.151172

52. Bro $F(1989)$ The diagnosis of Candida vaginitis in general practice. Scand J Prim Health Care 7(1):19-22. http://www.ncbi.nlm.nih. gov/pubmed/2657952. Accessed August 10, 2015 